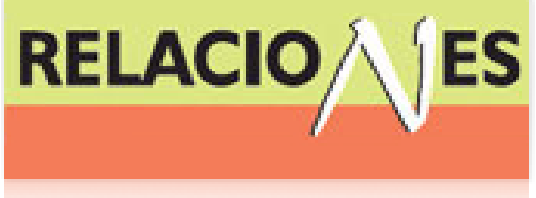

Relaciones. Estudios de historia y sociedad ISSN: 0185-3929

relacion@colmich.edu.mx

El Colegio de Michoacán, A.C

México

Schaffhauser Mizzi, Philippe

Las distancias de la cercanía. Una aproximación a la rivalidad regional entre Sahuayo y Jiquilpan, Michoacán

Relaciones. Estudios de historia y sociedad, vol. XXXIV, núm. 135, 2013, pp. 157-179

El Colegio de Michoacán, A.C

Zamora, México

Disponible en: http://www.redalyc.org/articulo.oa?id=13728260006

Cómo citar el artículo

- Número completo

- Más información del artículo

Página de la revista en redalyc.org

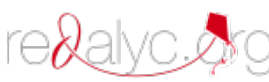

Sistema de Información Científica

Red de Revistas Científicas de América Latina, el Caribe, España y Portugal Proyecto académico sin fines de lucro, desarrollado bajo la iniciativa de acceso abierto 
SeCción General

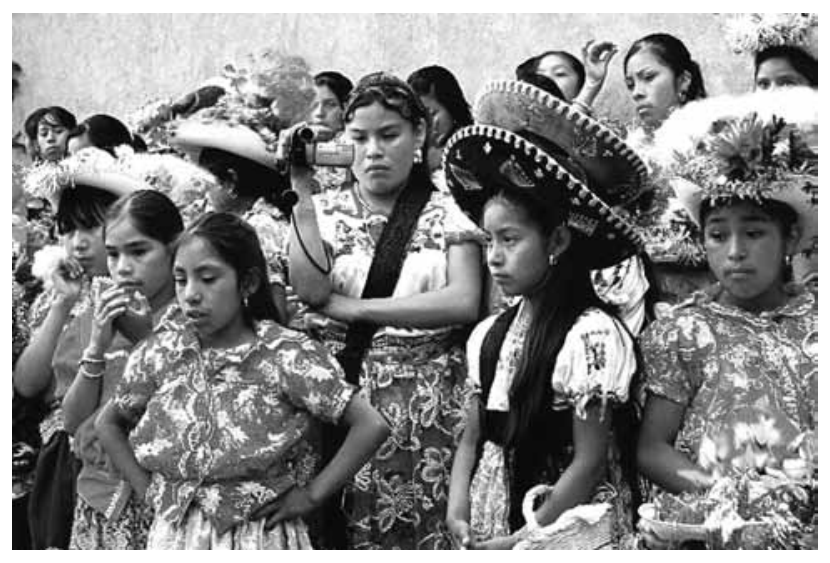





\title{
Las distancias de la cercanía. Una aproximación a la rivalidad regional entre Sahuayo y Jiquilpan, Michoacán
}

\author{
Philippe Schaffhauser Mizzi* \\ EL COLEGIO DE MICHOACÁN
}

Este artículo versa sobre el tema de la construcción de estereotipos culturales a través de uno de sus múltiples alicientes etnocéntricos, la rivalidad regional. Si bien, el fundamento de esta relación antagónica entre localidades vecinas puede derivar de un conflicto originario (el cual en el caso que nos ocupa se relaciona, sin duda, con el auge del cardenismo que convirtió a Jiquilpan en un centro político nacional), su actualidad a los ojos de los habitantes de ambos municipios cobra la forma de un chauvinismo exacerbado donde por un lado Jiquilpan aparece de manera esquemática como un municipio heredero de una cultura política de rancio abolengo que ha dado pie a un reconocimiento nacional y donde, por otro, Sahuayo combina su vocación comercial con su triple arraigo religioso sefardí, católico y cristero. Este contraste corresponde a una sobrerrepresentación que construye una brecha imaginaria entre los dos municipios ocultando la relación de cercanía y complementariedad que no ha dejado de existir entre ambos. En este sentido, las identidades locales se nutren de esta aparente distancia que corresponde a lo que Freud ya había señalado (1978, 55-56) como expresión de un "narcisismo de las pequeńas diferencias" o lo que Moisés Sáenz $(1939,113)$ describió como expresión de la fragmentación nacional donde cada comunidad, localidad y pueblo del país se convierte en una "patria chica" para sus habitantes. Bajo un enfoque constructivista, este artículo examina la construcción de algunos artificios identitarios cuyo propósito social no es tanto identificar lo propio en cada municipio, sino crear de facto una distancia entre ambos, tan artificial como inconmensurable, a través de la incorporación rutinaria en las prácticas sociales de representaciones sociales sobre el otro en tanto que "no jiquilpense" o "no sahuayense".

(Jiquilpan, Sahuayo, identidades locales, rivalidad, estereotipos)

*Schaffhauser@colmich.edu.mx 
Esos 5 kilómetros aunque parece, no sé, el muro de Berlín, esos 5 kilómetros en ese lugar en lugar de unirnos como que nos están separando. Pero tarde o temprano, tarde o temprano como $\mathrm{Za}$ mora y Jacona, tarde o temprano nos vamos a conurbar, tarde o temprano va a ser lo mismo, sí, pero somos necios, unos y otros. ${ }^{1}$

\section{INTRODUCCIÓN}

er rivales es compartir la hermandad del diferendo, la divergencia, el separatismo y finalmente la trama del conflicto. La particularidad de este último es unir y reunir primero en un mismo careo antes de provocar divorcio y enfrentamiento. Georg Simmel (1995), a principios del siglo pasado, y más tarde René Girard (1972) han insistido en el valor estructurante del conflicto, cuyo rostro antropológico y trivial es la rivalidad. En esta tesitura, Sigmund Freud señala lo siguiente:

En cierta ocasión me ocupé en el fenómeno de que las comunidades vecinas, y aun emparentadas, son precisamente las que más se combaten y desdeñan entra sí, como, por ejemplo, españoles y portugueses, alemanes del norte y del sur, ingleses y escoceses, etcétera. Denominé este fenómeno narcisismo de las pequeñas diferencias, aunque tal término escasamente contribuye a explicarlo (Freud 1978, 55-56).

En este sentido, Sahuayo y Jiquilpan son dos municipios separados por una misma cultura mestiza y ranchera que se inserta como extrapolación antropológica en la llamada zona de Jalmich. Asimismo, Sahuayo y Jiquilpan son dos municipios unidos por una misma rivalidad regional. Pero la rivalidad no es la guerra, aunque sea una de las tantas formas bajo la cual se manifiesta el conflicto cuya características principales, como bien sabemos desde los planteamientos al respecto de Georg Simmel (1995), consisten en regular las acciones recíprocas y construir el orden social. Este par de aseveraciones que describe y acota el marco interpretativo de las relaciones entre ambos municipios termina siendo una obviedad empírica para

${ }^{1}$ Entrevista con Miguel Ángel J.D., maestro del свтіs de Jiquilpan, 26/9/2008. 
quienes nos dedicamos a estudiar algún aspecto de la vida social y cultural en esta parte de la Ciénega de Chapala. En efecto, basta con escuchar lo que opinan los jiquilpenses acerca de los sahuayenses y viceversa, para darse cuenta pronto de la magnitud de la competencia que existe entre ambos municipios. Es un tema que no se toma a la ligera cuando se es oriundo de esa región. El problema sociológico que conlleva dicha rivalidad ha venido, poco a poco, a despertar mi curiosidad e interés. Ambos se desprenden de un proyecto de investigación sobre procesos migratorios que inicié en diciembre de 2007 (Schaffhauser 2008). Muchas voces jiquilpenses que me ha tocado entrevistar coinciden en señalar una suerte de discrepancia, oposición, diferencia, dualidad e incluso conflicto entre su municipio y Sahuayo. Paradójicamente, el vecino municipio contribuye a unir a los jiquilpenses en una sola identidad, más allá de sus propias diferencias y de los ańejos problemas que vienen arrastrando desde la "época dorada" del cardenismo. ${ }^{2}$

Con base en esta representación social, cuyos fundamentos como veremos más adelante son tan mitológicos como empíricos y que, sin duda, la población de ambas ciudades construye y comparte con frecuencia, este artículo pretende 1) dar a conocer las formas en que se está dando dicha rivalidad y 2) plantear une serie de pistas para interpretar el significado de la misma, esto es, ¿a qué tipo de fenómeno social y cultural nos estamos enfrentando los investigadores que nos dedicamos al tema?

No huelga decir que la presente reflexión se inserta en el campo de los estudios identitarios, en el entendido de que la oposición entre Jiquilpan y Sahuayo da pie a diversas, múltiples y cotidianas interacciones entre los habitantes de ambos municipios. A final de cuentas se trata de un ejemplo adicional de las llamadas identidades y rivalidades regionales. En este sentido, el caso Jiquilpan-Sahuayo no es en absoluto un caso aislado o extremadamente particular, pues dicho antagonismo podemos encontrarlo, a menudo, en otras partes del

${ }^{2}$ Con todas proporciones guardadas se consideraba en tiempos de Lázaro Cárdenas, entonces presidente de la república, que Jiquilpan era la segunda capital del país, situación de la cual se beneficiaron varios jiquilpenses al ocupar cargos públicos y responsabilidades oficiales. 
estado de Michoacán, empezando por la consabida emulación que existe entre Jacona y Zamora. El pedagogo mexicano Moisés Sáenz describía México como un país conformado de "patrias chicas" (Sáenz 1938) y el caso que me ocupa aquí no dista mucho de esta acertada definición del promotor del proyecto indigenista de Carapan. Asimismo, el hablar de rivalidad regional, es decir, de competencia en prácticamente todos los ámbitos de la vida social, es tan sólo una de las dos caras de una misma moneda. No podemos entender dicho antagonismo sin tener en cuenta el afán de cada uno de estos dos municipios por ser, al menos, protagonista regional.

Uno de los argumentos mayores de esta reflexión descansa en la fórmula lapidaria: el vecino es el otro, esto es, el otro cercano imprescindible para lograr cualquier tipo de experiencia colectiva y social. En otras palabras, si bien la distancia que separa a un municipio del otro no es geográfica, significa entonces que ésta cobra una dimensión altamente simbólica no sólo en términos semióticos, sino sobre todo como un modo de reconstruir la realidad en el entendido de que ésta surte efectos en las prácticas, hábitos, costumbres y representaciones que propician identificación y diferenciación entre las sociedades jiquilpense y sahuayense. Por ende, lo que a continuación expongo se caracteriza por su orientación teórica-metodológica construccionista. En efecto, la rivalidad que une y separa Jiquilpan de Sahuayo no es sino un proceso histórico, el cual, con el paso del tiempo, se ha vuelto natural y ha sido incorporado por las mentalidades de ambas localidades.

\section{JiQUiLPAN-SAHUAYO O LA ESTRUCTURACióN DE UNA DIFERENCIACIÓN}

En Jiquilpan ya no es un futuro para muchos. En Sahuayo hay servicios: centros comerciales como Aurrera o Soriana. ${ }^{3}$

Una rivalidad es siempre una suma de detalles que considerados por separado son nimios y hasta irrelevantes. Una rivalidad es a lo sumo

${ }^{3}$ Responsable del servicio de atención al migrante para el ayuntamiento de Jiquilpan. Entrevista del 11/01/2008. 
una manera de alumbrar los hechos siempre desde la misma mirada: el duelo. Una rivalidad como lo señala la etimología latina tiene que ver con el concepto de río que une y separa al mismo tiempo. En este sentido, el rival es aquel que transitaba por el río o vivía a orillas de él. Es a la vez el de enfrente, el propio vecino cuya cercanía no es bienvenida y motivo de suspicacia, desprecio, codicia, envidia, odio o rechazo. El juego de lenguaje de la rivalidad despierta conexiones y establece puentes semánticos $\mathrm{y}$, sin duda, pragmáticos (Wittgenstein 2002,109$)$ entre nociones como conflicto, duelo, antagonismo, competencia, emulación, diferendo, disputa, enfrentamiento, riña, gresca, reyerta, entre otras. También el lenguaje de la rivalidad abarca la idea de violencia verbal y simbólica o física y conativa. En situación de rivalidad, la identidad del uno y del otro se ensimisma en un círculo vicioso o se reflecta en un espejo donde el rival es uno mismo como bien lo señala René Girard con el tema harto sugerente del sacrificio y del chivo expiatorio (1982).

Hasta cierto punto, como es el caso de Jiquilpan y Sahuayo que nos interesa estudiar aquí, el hablar de rivalidad regional se torna tautológico. Es redundante porque el rival es siempre un otro cercano y el resultado de la eliminación de una familiaridad. En este sentido, los marcianos o campesinos neozelandeses no pueden ser rivales cuando se es nativo de Jiquilpan o Sahuayo. Al igual que el racismo, el chauvinismo, el patriotismo, el nacionalismo, el provincialismo, así como el irredentismo o el imperialismo, la rivalidad es, asimismo, una de tantas vertientes del etnocentrismo. Fue el sociólogo americano spenceriano William Graham Sumner (1840-1910) quien acunó el neologismo “etnocentrismo". Este concepto aparece por primera vez en la obra Folkways publicada en 1906 donde Sumner (1960) concibe el etnocentrismo en tanto que:

el "nombre técnico" para la tendencia a ver en su grupo el centro de todas las cosas y todos los otros grupos siendo evaluado con relación a éste. Es una alusión temprana al grupo de referencia. Define el "patriotismo" como la honradez al grupo cívico al cual se pertenece por el nacimiento o a cualquier otro lugar de grupo y el "chauvinismo" como una afirmación de sí mismo salvaje y jactancioso; es la expresión del mismo mecanismo 
de "compañerismo" hacia el grupo y de hostilidad con respecto a otro grupo (Merton 1997, 354).

Lo interesante de esta definición es que, además de devenir en problema antropológico de fondo (Lévi-Strauss 1961 y 1973) planteado por un sociólogo de gabinete, apunta a dos problemas conceptualmente maniatados, pues el etnocentrismo es siempre la expresión de una identidad social y cultural, toda vez que por identidad entendemos los científicos sociales un acuerdo moral sobre un gran número de cosas materiales y simbólicas y una situación cultural determinada. En este sentido, la presente reflexión contempla el problema de la rivalidad entre Sahuayo y Jiquilpan en tanto expresión de un mutuo etnocentrismo que bien podríamos caracterizar como comarcano, esto es, la exacerbación de pequeñas diferencias.

Para enmarcar la problemática relativa a dicha competencia regional echaré mano de tres conceptos básicos que facilitan el registro de datos empíricos sobre los cuales se montará mi análisis. Se trata de los conceptos de tiempo, cuerpo y espacio, en el entendido de que mediante el primero se pretende tocar el tema de los ritmos sociales, rituales religiosos y finalmente la organización de lo cotidiano; con el segundo es cuestión de comprender quienes son los jiquilpenses y los sahuayenses y cómo se proyectan en el mundo circundante o lejano; y para terminar importa tener en cuenta la relación que guarda cada una de estas dos microsociedades con su respectivo medio ambiente. En este sentido el municipio de Jiquilpan tiene una extensión territorial de $242.13 \mathrm{~km}^{2}$ que es casi el doble de la superficie del municipio de Sahuayo $\left(128.05 \mathrm{~km}^{2}\right)$, al tiempo que este último tiene casi el doble de población (esto es, $59,957)$ con respecto al número de habitantes domiciliados en Jiquilpan $(31,730)$. Vale decir que el territorio municipal de Sahuayo fue cercenado en varias ocasiones, en las cuales destaca la pérdida de una porción de $238 \mathrm{~km}^{2}$ para dar vida al municipio de Venustiano Carranza creado en 1935 (González 1979, 180). En otras palabras, el hablar hoy día de Sahuayo como ciudad o como municipio es casi lo mismo, situación que no sucede para el caso de Jiquilpan que se conforma de varias tenencias y decenas de ranchos. Esta realidad geo- 
gráfica surte, desde luego, efectos cuando se es de Jiquilpan o de Sahuayo. En efecto hablar de campo, de ruralidad, de cultura campirana, de agricultura, de ejidos tiene (o tenía) más sentido en Jiquilpan que en Sahuayo. En pocas palabras, para los ojos de turistas y visitantes ocasionales, Sahuayo tiene rostro de ciudad y Jiquilpan cara de pueblo tranquilo y tal vez adormecido. Sahuayo tiene una densidad demográfica de 468 habitantes que es más del triple de Jiquilpan cuya densidad demográfica es de sólo 131 habitantes por $\mathrm{km}^{2}$.

Con esta muy escueta descripción del entorno regional se entiende porque Álvaro Ochoa subtituló "una historia confinada" su investigación historiográfica dedicada al municipio de Jiquilpan, así como, porque mi entrańable compańero y colega de El Colegio de Michoacán, siendo nativo de Jiquilpan, menciona, dicho sea de paso, en su estudio el tema de ese antagonismo como si Sahuayo nunca hubiera existido (Ochoa 2003).

En un mundo pequeño, todos se conocían. Los domicilios, aunque tenían nombres las calles (La Rana, Santa Anita, San Cayetano, la Calle Real, la Alcantarilla, etc.) siempre se daban por las señas: por en ca’ dońa Pachita la Pureza, por en ca' Rosendo el Pío, por el mesón de Munguía [...] Era suficiente cualquier dato de estos para dar con el domicilio buscado. Los muchachos de los diferentes barrios formábamos palomillas y con frecuencia entablábamos batallas campales a pedradas, los de San Cayetano, los de Santa Anita, los de la Puentecita [...] pero si se trataba de ir contra los de Sahuayo, todos estábamos unidos y nos olvidábamos de nuestras diferencias (Bravo Sandoval 1998, 11-12).

Esta cita que bien podría caracterizar cualquier época de la vida social en Jiquilpan, indica, sin embargo, como me lo comentó Álvaro Ochoa, en el transcurso de una conversación que recientemente tuve con él, ${ }^{4}$ que la rivalidad entre Sahuayo y Jiquilpan es anterior al cardenismo y sólo se le puede imputar al general el haber incrementado los factores que participaron en la reproducción de la misma.

${ }^{4}$ Conversación con don Álvaro Ochoa, El Colegio de Michoacán, Zamora, 11 de septiembre de 2009. 
¿Cómo empezó dicho antagonismo, pues quién sabe? Sin embargo, la existencia de un hueco historiográfico para documentar los orígenes de esa rivalidad no impide que cobre actualidad y surta efectos en muchos de los campos de la vida social tanto en Sahuayo como en Jiquilpan.

Con respecto al estudio monográfico que don Luis González y González realizó para el municipio de Sahuayo (González 1979), son aún más escasos los elementos referentes a este tema a sabiendas de que éste no era el centro de atención del autor de Pueblo en vilo. ${ }^{5}$ De detenerse la mirada sobre el rubro religioso, destaca lo siguiente: La fiesta principal de Sahuayo es la celebración de Santiago Apóstol similar a la de Zapopan celebrada el 12 de octubre. Los sahuayenses salen a la calle ya sea para desfilar o presenciar la procesión de los Tlahualiles que visten sus lujosos, exuberantes y pesados atuendos de danzantes con sus impresionantes máscaras. Son personajes míticos que remiten al pasado precolombino y azteca. Para los ojos de propios y extrańos dichas figuras de las tradiciones locales se asemejan, de modo fantástico, a demonios. La fiesta de Santiago se realiza el 25 de julio y cobra la forma de un carnaval ya que se despliega en una semana entera. ${ }^{6}$

La fiesta principal en Jiquilpan es, en cambio, la celebración de la expropiación petrolera de 1938, cuando el principal hijo de Jiquilpan, Lázaro Cárdenas del Río era presidente de México. Cae el 18 de marzo. La una es religiosa, sincrética y de alguna manera pagana en

${ }^{5}$ Otro elemento que podemos verter al expediente sobre la rivalidad entre Sahuayo y Jiquilpan tiene que ver con el hecho de que Jiquilpan en un momento dado fue cabecera de San José de Gracia (el pueblo se llamaba en aquel entonces Ornelas, en honor a un general juarista quien había defendido la plaza de Jiquilpan ante el ejército francés durante la Guerra de Intervención), de donde es oriundo don Luis González y González, antes de su separación para conformar el municipio de Marcos Castellanos en 1967, y a partir de 1981 el nombre de su cabecera volvió a cambiar para ser de nuevo San José de Gracia. De alguna manera Pueblo en vilo es una suerte de alegato contra la posición hegemónica que ejercía Jiquilpan en tiempos de la Guerra Cristera. Dicho de otra manera, durante la Guerra Cristera, Jiquilpan representó, a pesar de la complejidad y de la gama de representaciones y creencias cívicas y religiosas de sus habitantes, un territorio agrarista rodeado por municipios y pueblos "fanáticos".

${ }^{6}$ Lo cual no deja de sorprender al visitante poco acostumbrado a presenciar un carnaval en pleno verano. 
tanto que la segunda es civil, revolucionaria y finalmente cardenista. En la primera corean los participantes el nombre del papa y de Cristo Rey aludiendo así al pasado cristero y conservador del Sahuayo de los años veinte del siglo xx; en la segunda, "los feligreses de la revolución santificada” comulgan y comparten con el prójimo su fe en el cardenismo de antaño con tal de exhortar a los políticos locales y nacionales a respetar este patrimonio político nacional. Los jiquilpenses piensan que México los mira cada vez que celebran el 18 de marzo. Los sahuayenses consideran, en cambio, que el 25 de julio es motivo para atraer más turistas michoacanos y de los estados aledaños.

En cada uno de estos eventos los sahuayenses y los jiquilpenses se acomiden y se esmeran para celebrar, con alarde de detalles y creatividad, su propia comunidad y los lazos que entraña. En ese contexto, parece que los blancos (o blanquiazules) viven del lado de Sahuayo y los rojos (y amarillos del Sol Azteca) viven del lado de Jiquilpan. La celebración del 18 de marzo que es un homenaje al desempeño del general presidente Lázaro Cárdenas se ha vuelto religión comunal, al tiempo que, la fiesta de Santiago en Sahuayo inaugura una semana de Carnaval que, como suele suceder, desborda el marco estricto del catolicismo institucional. No está de sobra decir que primero Sahuayo era dependencia religiosa de la diócesis de Jiquilpan en los albores de la colonia.

Como suele suceder cuando de comprender la realidad social actual se trata, parte de la explicación de los fenómenos que el observador tiene ante él se originan en el pasado. El presente de Sahuayo y Jiquilpan no escapa a esta regla metodológica. Para atender el tema de los antecedentes históricos de la rivalidad entre Sahuayo y Jiquilpan el sociólogo puede echar mano de varias fuentes entre las cuales destacan las ya citadas monografías de Álvaro Ochoa (2003) acerca de Jiquilpan y don Luis González (1979) sobre Sahuayo, además de los estudios históricos y sociológicos sobre la ex hacienda de la Guaracha de Heriberto Moreno (1994) y John Gledhill (1991), cuyo casco original se encuentra a escasos kilómetros de Jiquilpan en la comunidad ejidal de Emiliano Zapata, municipio de Villamar.

Otra fuente a la cual quiero remitirme de modo privilegiado para atender los antecedentes históricos de esta rivalidad es el artículo de 
Jorge Zepeda Patterson (1989) quien toca precisamente el tema de la oposición entre Jiquilpan y Sahuayo, mediante el papel central que tuvo la hacienda de Guaracha en la construcción de la misma. El argumento de Zepeda consiste en decir que no se puede entender nada o muy poco de la actual rivalidad si se soslaya el papel económico, político y hasta cierto punto cultural del latifundio de Guaracha. He ahí la tesis de las estructuras sociales que están en las bambalinas del escenario conflictual comarcano que une y separa a ambos municipios. Según Zepeda, la especialización política de Jiquilpan y económica de Sahuayo se remonta a los últimos años del siglo XIX (Zepeda 1989, 71). Ambas destrezas son el resultado de las relaciones que trabaron Jiquilpan y Sahuayo con respecto a Guaracha y surtieron efectos hasta hoy en día, pues se considera, a menudo, que Jiquilpan es tierra de políticos y servidores públicos en tanto que Sahuayo es cuna de comerciantes y devotos católicos. Sin hacer alarde de teoría social de corte marxista, estas virtudes tienen un trasfondo histórico y una base material. Guaracha obligó a cada uno de estos municipios a decidir sobre su porvenir social ya sea político o económico.

En este sentido, la tesis de Zepeda consiste en decir que la hacienda que reinaba en aquel entonces sobre la Ciénega de Chapala se encuentra en el origen de la rivalidad entre Sahuayo y Jiquilpan. Despojo de tierras en detrimento de los intereses de propietarios y campesinos jiquilpenses con tal de saciar la voracidad del extensionismo ganadero de Guaracha, por un lado, y la necesidad de que la hacienda contase con un mercado para suministrar lo faltante, por otro, provocó que, en esta tesitura, se fuera especializando Sahuayo y por tanto alejando de Jiquilpan. Años más tarde Jiquilpan, en las postrimerías del porfiriato, supo mejor sacar provecho de los embates revolucionarios, por cierto poco compatible con el sosiego que necesita el comercio en general y los intercambios económicos entre los pueblos de la Ciénega en particular (Zepeda 1989, 74), para convertirse en la cuna de varias camadas de funcionarios públicos de medio y alto rango regionales y hasta nacionales. Es interesante notar dicho sea de paso que fue en esa época, en 1891, que Sahuayo cambia su nombre oficial por el de Sahuayo de Porfirio Díaz (Zepeda 1989, 71). 
La especialización diferenciada de Jiquilpan y Sahuayo tiene varias consecuencias sociológicas sobre cómo se construyen en la actualidad las representaciones sociales acerca de ambos municipios. Primero, esta construcción histórica devino en una identidad social característica de cada ciudad, esto es, un proceso de naturalización, interiorización e incorporación de un orden social implícito (Bourdieu 1980), todo lo cual termina por ocultar la fuerza y el peso del pasado, es decir, el resultado de luchas y conflictos en torno a la revolución mexicana pero con un sesgo regional donde tanto la Guaracha como la figura del general Lázaro Cárdenas del Río son esenciales para la comprensión de los intereses y embates que construyeron las relaciones entre Jiquilpan y Sahuayo en rivalidad local. Esto implica y abre camino para una historiografía acuciosa sobre los antecedentes que condujeron o indujeron esta oposición y cabe mencionar que su implementación rebasaría los límites tanto de mis competencias académicas como del espacio de este artículo. Segundo, la construcción de la rivalidad entre Sahuayo y Jiquilpan induce la idea de una dualidad que termina por soslayar la complejidad de las relaciones sociales en el interior de cada uno de estos municipios tanto hoy como desde luego ayer. Tan solo mencionaré dos elementos de discusión para apuntalar esta última idea. Ambos remiten al municipio de Jiquilpan. El primero tiene que ver con la visión estereotipada con que se califica la población económicamente activa en cada municipio: empresarios y comerciantes en Sahuayo y políticos y maestros en Jiquilpan; lo cual pasa por alto, por no decir coarta o sofoca, la posibilidad de identificar, por un lado, una fibra comercial y la capacidad de emprender del jiquilpense y, por otro, la cultura política del sahuayense, siempre que se considere que ser creyente y católico es también una postura política y la construcción de valores colectivos y nacionales. Es interesante ver el número significativo de jiquilpenses que tuvieron éxito en el campo de los negocios, a través de la migración internacional a los Estados-Unidos.?

${ }^{7}$ Hacia 2008, la presidencia municipal de Jiquilpan, a través de la oficina de atención al migrante, quería identificar a los jiquilpenses migrantes exitosos en distintitos campos como las artes (Damián Alcázar o el pintor Juan Rayas), el deporte (Germán Villa) y el negocio, actividad en la cual varios hijos de Jiquilpan habían destacado. 
Segundo, la fe, el catolicismo y la religiosidad se equiparan al fervor de los sahuayenses. Basta mencionar las procesiones multitudinarias de niños, adolescentes, mujeres y hombres de Jiquilpan coreando el nombre de Cristo Rey, a principios de diciembre en víspera de la celebración de la virgen de Guadalupe, para darse cuenta de la importancia que cobra la institución religiosa para los jiquilpenses. Basta mencionar, en los treinta del siglo pasado, el empeño del propio Lázaro Cárdenas en hacerse del fervor de los jiquilpenses de las demás tenencias por sus cultos, como fue el caso de la "centralización" de la procesión de la virgen de los Remedios característica de San Martín Totolán y los Remedios y que, por orden del general, tenía que culminar en la mismísima cabecera municipal. ${ }^{8}$

Asimismo, la rivalidad entre Sahuayo y Jiquilpan es asunto demográfico, geográfico y político. Si bien el nombre de ambos poblados es de origen indígena, ya que el nombre completo de la tierra de los Cárdenas es Jiquilpan-Huanimban y para el segundo se deriva del náhuatl tzacual-ayotl (i.e. vasija que tiene el aspecto de una tortuga) y si bien ambos municipios fueron elevados al rango de villa en el mismo año de 1891, no deja de llamar la atención que el nombre oficial de Sahuayo hasta 1967 era Sahuayo de Porfirio Díaz, cuando el de Jiquilpan era y sigue siendo Jiquilpan de Juárez. Curiosa es la referencia durante tanto tiempo a aquel personaje tan controvertido en la historia mexicana a diferencia de Jiquilpan que es pueblo natal del general Lázaro Cárdenas, quien es un baluarte simbólico de la Revolución mexicana.

La rivalidad entre Sahuayo y Jiquilpan ha venido a cobrar una dimensión política cristalizando aún más las diferencias entre la cultura y las tradiciones cívicas de cada municipio. Hace pocos años, al igual que Jiquilpan y los demás municipios el estado de Michoacán, las autoridades de Sahuayo planearon edificar un arco señalando el ingreso al municipio. Pero por problemas de contigüidad con el territorio municipal de Jiquilpan y aprovechando el tra-

${ }^{8}$ Comunicación personal con Pedro Chalé, en paz descanse. 
mo de la calzada que separa Sahuayo de su vecino, las autoridades sahuayenses decidieron implantar dicho arco municipal en esa vía. El problema es que ésta se encuentra en territorio municipal jiquilpense, situación que provocó la ira de las autoridades municipales jiquilpenses que vetaron terminantemente la construcción de dicha obra. A escasos metros de ahí en territorio aún jiquilpense, se encuentra un centro de convenciones, grande, espacioso, moderno, funcional e incluso majestuoso. Fue escenario no hace mucho tiempo de recitales impartidos por Vicente Fernández o Juan Gabriel, los cuales despertaron una enorme pasión en toda la región. El dueño de ese centro es oriundo de Sahuayo y arrenda también el espacio para fiestas de graduación en las escuelas locales, bodas, bautizos para las acaudaladas familias de la región y para mítines y actos políticos. Al dueño se le ocurrió poner en el letrero colocado en el techo del impresionante edificio "Centro de Convenciones de Sahuayo". Ante esta realidad, las autoridades municipales jiquilpenses reaccionaron y exigieron que se retirara la mención de "Sahuayo", lo cual consiguieron quedando sólo la inscripción "Centro de Convenciones".

En otro tema, Jiquilpan cuenta con una radiodifusora que lleva el nombre del municipio. En la actualidad, se encuentra, sin embargo, en el territorio municipal de Sahuayo. En los años setenta transmitía desde las instalaciones del Centro de Estudios de la Revolución Mexicana (CERM). Tenía para aquel entonces varios programas y contaba con el patrocinio de comerciantes de Sahuayo a través del pago de anuncios y comerciales. Empezó, no obstante, una campaña de promoción hacia los productos comercializados en las tiendas de Jiquilpan en detrimento de los expendios sahuayenses cuyas mercancías se consideraban de poca calidad. Ante el enojo de los comerciantes sahuayenses aludidos que amenazaban con retirar de inmediato su apoyo económico para la radio, dicha campaña fue ipso facto retirada.

En otra tesitura, cuando se transita por la entrada que conduce al centro de Jiquilpan desde la carretera que procede de San José de Gracia y Colima es de llamar la atención, para quienes estamos un poco enterados de la situación del municipio, la presencia de una 
letrero vial que anuncia enfáticamente Jiquilpan 98,000 habitantes, ${ }^{9}$ es decir, más del triple de la población total del municipio. Es más, si se tiene sólo en cuenta la población de la cabecera municipal el número de habitantes desciende a 23,132 habitantes, al tiempo que los 8,598 habitantes jiquilpenses restantes se diseminan entre la miríada de tenencias y ranchos que conforman el territorio municipal. Bajo este contexto, se da un fenómeno en Jiquilpan que no existe o no pasa de ser incipiente en Sahuayo y cuya medición por la Sedesol y el INEGI permite tener muy en cuenta lo que son la complejidad, las brechas y los desfases socioeconómicos que se van creando en el municipio, pues se trata de la marginación en el interior del municipio. Considerada la extensión territorial de Jiquilpan, se necesita, por ejemplo, cerca de una hora para enlazar la cabecera municipal de Jiquilpan con la comunidad de Los Paredones. El único transporte colectivo está a cargo de un señor muy desanimado para seguir con su labor por las trabas que las autoridades de Morelia le habían puesto para el desempeño del mismo. Si bien la población de Sahuayo sigue creciendo con regularidad desde 1900 hasta la fecha, el caso demográfico de Jiquilpan es muy distinto ya que se está dando un decrecimiento significativo de la población desde 2000. Esta información se corrobora cuando se desglosa la evolución demográfica del municipio. De acuerdo a informaciones censales del INEGI del 2005, las siguientes localidades desaparecieron del mapa municipal de Jiquilpan convirtiéndose en pueblos, ranchos o caseríos fantasmas. Se trata de 26 localidades. ${ }^{10}$

${ }^{9}$ El puente de Sahuayo que da la bienvenida a todos aquellos visitantes que pasan por ahí, dice: "Sahuayo, población aproximada 110,000 habitantes", cuando, en realidad, la demografía del municipio no alcanza los 60,000 habitantes de acuerdo al último censo intermedio de 2005 del INEGI.

${ }^{10}$ La Nopalera, Las Violetas, La Casa de Mora, San José, Equipo de Bomberos de Totolán, Las Puentes, La Morera, Rancho Alegre (Colonia Loma del Pastor), los Cerritos, Los Amoles, Las Pajas (El Tubo), La Casa Blanca, Los Chiqueros, El Capulín, El Cerezo, La Purísima, La Bolsa, La Buyera, Hotel Fiesta Kaminchín, El Junco, Jiquilpan de Juárez 1., Rancho de Adán Gálvez, Rancho de Alfonso Amezcua, Rancho de José Magaña, Rancho de José María Barragán, La Beneficencia (La Morena). El INEgi en el conteo de 2005 da una lista total de 59 localidades para todo el municipio. 
Asimismo, vale señalar el descenso demográfico sufrido en los últimos años por el municipio mediante el cual resalta el caso de las siguientes localidades:

- Jiquilpan (cabecera) pasa de 25,901 habitantes en 1995 a 23,132 en 2005;

- Los Remedios de 3,871 en 1990 a 1,455 en 2005;

- Francisco Sarabia (Cerrito Pelón) de 2,239 en 1990 a 1,635 en 2005;

- Abadiano (Los Bajos) de 1,347 en 1990 a 786 en 2005;

- Santa Bárbara de 1,137 en 1990 a 362 en 2005; y

- Paredones de 915 en 1970 a 284 en 2005.

Significa que el caso de Jiquilpan no sólo se asemeja a la situación demográfica por la cual atraviesa el estado de Michoacán, sino que construye las bases para convertir a Jiquilpan en un "pueblo chico" frente al auge comercial de Sahuayo que amenaza con absorber a su vecino. Parte de la rivalidad se acrecienta con la transposición a tierra michoacana de la mítica riña entre David y Goliat.

En esta tesitura es interesante mencionar el caso de la tenencia de Francisco Sarabia que pertenece al municipio de Jiquilpan, cuya ubicación, sin embargo, coloca al poblado a escasos metros donde principia el municipio de Sahuayo. Para aquellos lugareños de Francisco Sarabia su vida está más volcada del lado de Sahuayo, tanto en el plano económico (como lo ejemplifican la existencia de pequeńos talleres textiles instalados en Francisco Sarabia que trabajan a destajo para medianas y pequeñas empresas de Sahuayo), como en el campo religioso como lo simboliza la peregrinación a Santiago Apóstol que realizan habitantes de Francisco Sarabia a la iglesia de Santiago ubicada en Sahuayo. Sólo hay un paso para pensar que este proceso de acercamiento entre una tenencia de Jiquilpan y el municipio de Sahuayo suena también a una forma de irredentismo sahuayense para restarle poderío a Jiquilpan.

Otro dato aparentemente nimio pero sí muy interesante notar: llama también la atención la señalización carretera que forma parte del manejo territorial en esta parte del estado de Michoacán y con incursiones en el vecino estado de Jalisco, pues para quienes transi- 
tan por esos rumbos se menciona en los letreros más a Jiquilpan que a Sahuayo. Los motivos son tal vez muchos, pero tiene que ver, sin duda, con el esmero que puso el general Cárdenas para convertir, al menos, Jiquilpan en una referencia política regional. No hay que perder de vista que Jiquilpan es oficialmente uno de los catorce distritos electorales que conforman la geografía política y democrática del estado de Michoacán, situación que a decir de voces jiquilpenses no deja de propiciar molestia y celos de Sahuayo y trabar el afán de protagonismo del vecino municipio. En materia de comunicación es interesante mencionar que hasta hace tiempo en los directorios telefónicos del estado de Michoacán, los teléfonohabientes de Jiquilpan estaban incluidos en el listado referente a Sahuayo. Se marcaba siempre a Sahuayo sin importar que el usuario radicase en Jiquilpan. No había desglose y por decirlo así, en tanto colectivo, Jiquilpan no contaba con una "identidad telefónica".

La situación socioeconómica que se vive en cada uno de los municipios convierte a Sahuayo en un polo de desarrollo cuya base es el comercio y algunas producciones tradicionales (como el calzado, los huaraches y la fabricación de sombreros) en tanto que la economía municipal de Jiquilpan gira alrededor de la agricultura fundamentalmente ganadera, como lo ejemplifica la presencia de una planta LICONSA procesadora de leche instalada desde los setenta.

Como me comentaba don Jorge Romero, ${ }^{11}$ quien en dos ocasiones llegó a ser presidente municipal de Jiquilpan, el general Cárdenas si bien apostó a la reforma agraria, al igual que para el resto del país, con tal de solucionar el problema social en Jiquilpan, consideró que el futuro del municipio apuntaba al desarrollo de la educación y de la ecología (González 1979, 210). Jiquilpan cuenta con varios espacios naturales y sitios de esparcimiento como son los bosques Juárez y Cuauhtémoc o la Unidad Deportiva, sin parangón en toda la Ciénega de Chapala. Tomando en cuenta el papel y el peso que ha tenido la familia Cárdenas en la historia y el desarrollo del municipio, tal vez no es mucho exagerar el decir que Jiquilpan es en realidad ciudad-Cárdenas.

${ }^{11}$ Entrevista del 17 de junio de 2008. 


\title{
ESTEREOTIPOS CRUZADOS: ESTIGMA E IDEAL-TIPO ENTRE SAHUAYO Y JiQUiLPAN
}

\begin{abstract}
Mira, Sahuayo es una mezcla, dicen ellos, de franceses, judíos e hijos de puta. [...] Perdón. Sí, mira, el sahuayense es un tipo inteligente. No vas a encontrar comerciantes más hábiles que él en toda la república, es más ni siquiera los del barrio bravo de Tepito. El sahuayense te vende los calcetines que traes puestos.
\end{abstract}

J.L. C.G., periodista de y en Jiquilpan.

Entre sus varios ensayos interaccionistas, el sociólogo Erving Goffman dedica una serie de observaciones y reflexiones sobre el problema del estigma que siempre irrumpe en las relaciones sociales más cotidianas (Goffman 1963). En términos heurísticos me parece oportuno echar mano de esta fuente para ir interpretando algunas de las facetas bajo las cuales jiquilpenses y sahuayenses se representan a sí mismos y a los de al lado. Son imágenes de contraste, manera de enfatizar defectos imputados a lo ajeno o de sobrevalorar cualidades atribuidas a lo propio.

Ramón Sánchez, erudito y ensayista local, escribe a fines del siglo xix que los jiquilpenses son "Ilustrados y... muy amantes de música” (Bravo Sandoval 1998, 11), lo cual, de modo pragmático y de acuerdo al contexto de rivalidad regional que nos ocupa, significaría que los de Sahuayo ni son ilustrados ni tampoco hayan sido amantes algún día de música. Se dice por ejemplo, en Jiquilpan, que Sahuayo es para trabajar y Jiquilpan para vivir. De hecho, al igual que en otras parte del estado y dada la llamada crisis del campo, muchos terrenos han venido a ser fraccionados para fines inmobiliarios. Entre estas especulaciones y deseos de cumplir con un proyecto sońado, hay varios casos de sahuayenses que han comprado lotes o casas en Jiquilpan por ser un pueblo no tan bullicioso como Sahuayo. El fenómeno de las quintas domingueras y fiesteras se está dando en Jiquilpan, convirtiendo a este municipio en lugar de esparcimiento para el sector económico acaudalado de Sahuayo. En esta tesitura es interesante mencionar dicho sea de paso el proyecto o mejor dicho la intención de las autoridades de Jiquilpan de convertir al municipio en "pueblo mágico" al igual que el vecino pobla- 
do jalisciense de Mazamitla. La existencia por ejemplo del Museo de la Revolución en Jiquilpan dedicado en buena parte al culto del general Cárdenas y la celebración de sus hazañas, junto con la presencia de murales de José Clemente Orozco en varios sitios céntricos de la ciudad, son, sin duda, elementos claves para lograr este designio, propiciando una suerte de turismo nacional histórico-político, incentivando una forma de peregrinaje cívico. Sin embargo, falta mucho aún por conseguir ese sueño. ${ }^{12}$ La revolución y el agrarismo se convierten en aliciente para el desarrollo de la actividad turística generadora de divisas. Sin embargo, entre el sueńo de las autoridades y la realidad hay un buen trecho que recorrer de modo que no se avecina pronto tal oportunidad para sacar adelante la economía municipal. ${ }^{13}$

El dicho popular arriba mencionado remite también a otras representaciones que sobre Sahuayo construyen los jiquilpenses. Se pone de relieve que Sahuayo es un pueblo cristero, fanático, mocho de alguna manera, comerciante ${ }^{14} \mathrm{y}$ conservador al tiempo que Jiquilpan es revolucionario, agrarista, cardenista y de alguna manera nacionalista. Cuando se es de Jiquilpan, a los sahuayenses se les llama "tlahualiles" refiriéndose a aquellas figuras precolombinas que escenifican la celebración a Santiago Apóstol. En este contexto es un término despectivo, ya que se exageran de más las conductas religiosas de los sahuayenses. El sahuayense es harto devoto en tanto que el jiquilpense es juzgado como rábano, rojo por fuera y blanco por dentro, que describía la mentalidad y la cultura del militante comunista de los años setenta del siglo xx. Me tocó presenciar en 2008, la celebración del 20 de noviembre en Jiquilpan que de alguna manera

${ }^{12}$ Según comenta el actual presidente municipal de Jiquilpan, Mtro. Francisco Mora Ciprés, no se ha logrado un acuerdo con SECTUR e instancias internacionales como la UNESCO para concretar este proyecto cuyo primer paso consiste en habilitar la infraestructura de Jiquilpan de acuerdo a los requerimientos que dispone la denominación controlada "Pueblo Mágico".

${ }^{13}$ El 27 de noviembre del 2012, Jiquilpan recibió el nombramiento de Pueblo Mágico y tiene hasta mayo de 2013 para hacer los arreglos necesarios que mantengan la distinción (Nota del editor).

${ }^{14}$ Es interesante mencionar aquí la iniciativa de un puñado de comerciantes jiquilpenses en los setenta, quienes por no depender de la cámara de comercio e industria de Sahuayo pidieron afiliarse a la de Zamora. Su solicitud nunca prosperó. 
por el esmero de las autoridades en logar tener un evento grato y solemne para los habitantes del municipio se equiparó a la celebración de la expropiación petrolera, evento magno para Jiquilpan y testimonio de la lealtad local hacia la familia del general Cárdenas, a la cual también acudí. Después de presenciar momentos claves del festejo del 20 de noviembre (desfile, congregación en el estadio 18 de marzo y discursos de las autoridades para refrendar el compromiso revolucionario para con el pueblo mexicano) me fui, minutos después, a Sahuayo y pareciera que había llegado a otro mundo, otros país guiado por otros valores y regidos por otras normas. Allí ninguna mención de la Revolución, sus logros y sobre la importancia ciudadana de siempre recordarla. Esta pequeña experiencia de trabajo de campo permite acercarse a lo que hace tan distinto a un municipio del otro, y es una entrada para ir explorando esas diferencias como las perciben los propios pobladores de ambos municipios.

En otro tema, se cree que Jiquilpan es un poblado orientado hacia la cultura y la educación, además de haber heredado el legado político de la familia Cárdenas. En este sentido, vale mencionar que el municipio de Jiquilpan cubre todo el itinerario educativo desde la preescolar hasta la educación superior con la presencia del Instituto Tecnológico cuya matrícula se eleva en más de 1,700 alumnos que concurren de todo el estado para estudiar ahí. Es más, Jiquilpan cuenta con dos unidades de investigaciones en ciencias sociales, el CIIDIr que depende del Instituto Politécnico Nacional (creado por Lázaro Cárdenas) y la UAER (Unidad de Análisis y Estudios Regionales) que pertenece a la UNAM (donde estudió Cuauhtémoc Cárdenas Solórzano). En este rubro, Sahuayo cuenta sólo con la reciente creación de la Universidad de la Ciénega que todavía no estrena sus instalaciones, cuya construcción no ha culminado. Esto apunta a pensar que por lo regular se tiene la idea que el joven jiquilpense es más culto que su coetáneo sahuayense. En Jiquilpan se plantea la idea que el sahuayense es mocho y analfabeta partiendo del supuesto que, conforme a un precepto cristiano, "aumenta el dolor de uno mientras más crece su conocimiento". En torno a la Universidad (itinerante en los hechos) de la Ciénega de Chapala se desató una vez más una polémica y un motivo adicional para ali- 
mentar la rivalidad entre Jiquilpan y Sahuayo. El municipio de Jiquilpan considera que dicha universidad sahuayense es también parte de Jiquilpan, ya que algunas instalaciones de esa casa de estudios se encuentran también en territorio jiquilpense.

Lo anterior orienta las opiniones a creer que el jiquilpense tiene una cultura cívica y política más marcada que su compañero de Sahuayo (González 1979, 139). En el ámbito político el elector sahuayense es panista, tanto como fue sinarquista (González 1979, 195) o priista, en tanto que el electorado jiquilpense es perredista o priista, ${ }^{15}$ en el entendido de que tanto una como otra preferencia electoral jiquilpense guardan un especial apego y carińo hacia el cardenismo y su herencia en la región. Sin embargo, como lo señala Álvaro Ochoa (2003, 309), el blanquiazul llegó a ser en 1971 la alternativa política para una parte del electorado jiquilpense harto del cardenismo y de sus distintas expresiones heredadas de Lázaro Cárdenas o de su hermano, Dámaso Cárdenas. Jiquilpan era JiquilPAN. Dicen los sahuayenses acerca de su ciudad que es "la reina de la Ciénega”. Asimismo, al general Cárdenas se le apodaba de modo muy despectivo de "chicharronero" ya que, buena parte de la rivalidad que une a Sahuayo con Jiquilpan procede del intervencionismo de Cárdenas en la región y de los favores que concedió al municipio que lo vio nacer.

\section{Consideraciones finales}

Es obvio que toda esta sarta de diferencias y oposiciones entre Sahuayo y Jiquilpan tienen que ser ponderadas y contextualizadas. $\mathrm{Si}$ atendemos el campo de las prácticas religiosas, es de notar que el apego a la religión es, a veces, tan fuerte en el municipio como lo es

${ }^{15}$ De acuerdo al PREP del Instituto Electoral de Michoacán, los últimos comicios municipales celebrados el pasado 13 de noviembre de 2011 arrojan resultados que contradicen o matizan esta afirmación, ya que por primera en la historia de las elecciones locales, el PAN llegó al segundo lugar de la preferencia política (38.69\%) en Jiquilpan, dejando el primer lugar al candidato del PRD $(40.47 \%)$ por unos cuantos votos y relegando en tercer sitio muy lejos al PRI (17.18\%). Dicho sea de paso, es interesante ver que la participación electoral de los ciudadanos fue más importante en Sahuayo $(58.6 \%)$ donde ganó el Pan que en Jiquilpan (49.8\%) 
en Sahuayo. Basta mencionar el peregrinaje a la virgen de los Remedios en San Martín Totolán, la fiesta de San Cayetano en julio o las peregrinaciones decembrinas femenina y luego masculina con antorchas y faroles al santuario de la virgen de Guadalupe, momento en que acuden muchos migrantes.

La rivalidad entre Sahuayo y Jiquilpan, si bien es regional, cobra una dimensión universal pues es parte del proceso de socialización y "culturalización" que experimentan cada pueblo con lo que se considera ser su otredad más cercana. Asimismo, en esta relación diádica, el referente constante es México, país real o nación soñada, México de hoy día o México de antaño. El México hacia el cual hemos de proyectarnos o frente al cual es necesario trazar una raya que marque diferencia y oposición. La diferencia que resaltan tanto los sahuayenses como los jiquilpenses para afianzar su propia identidad local necesita de un tercero hacia el cual identificar y encontrar motivos y valores para justificar posiciones antagónicas. De alguna manera lo que muestran una y otra población son maneras distintas de considerarse mexicanos. Parece que los tiempos políticos que se viven hoy en México son sahuayenses, el pasado es jiquilpense.

Ahora bien, es cierto que dicha rivalidad oscila entre el folclor y posturas identitarias radicales. En este sentido, los políticos locales de ambos municipios tienen un papel muy importante ya sea para enfatizar o relativizar todo aquello que motiva o permite la diferenciación social entre ambas poblaciones. A los ojos de cualquier visitante de la región, no es mucha la diferencia entre sahuayenses y jiquilpenses y termina siendo un problema nimio sólo para querer salir una vez más en la foto. Sin embargo, aun cuando parezca un asunto pueril e irrelevante, las identidades locales marcan siempre una pauta para que los pobladores de un municipio determinado, por encima de sus diferencias sociales y culturales, cierren filas y se sientan parte de un algo distinto, diferente y que no se puede revolver con otro elemento social o conjunto cultural. Esto es, independientemente de que los fundamentos en que estriba tal o cual expresión identitaria sean falsos o fruto de una mera construcción política. Ser de Sahuayo no tiene sentido si al lado no hay un Jiquilpan que piense de modo simétrico y por tanto complementario. 
Hablar de rivalidad entre Sahuayo y Jiquilpan no es sino empezar a problematizar los etnocentrismos regionales.

La sociología crítica parece haber atendido lo suficiente el tema de las identidades regionales mostrándonos cuan artificial es su trasfondo cultural. La división de un territorio en regiones, sea cual sea el referente nacional, no es más que la implementación política (en el sentido de pública y colectiva) de una división (si consideramos que existen distintos puntos de vista y maneras de ver e interpretar lo que es un territorio) que satisface unos cuantos intereses económicos, políticos (en el sentido partidario), religiosos y culturales imperantes al crear ilusiones identitarias bien fundadas (Bourdieu 1980, 68). Sin embargo, las rivalidades como las identidades locales contribuyen a construir el camino de la socialización de los sujetos. En este sentido, no es lo mismo haber nacido en Jiquilpan o en Sahuayo. Ninguna explicación sociológica o antropológica logra copar por completo la expresión de tal ambivalencia, ya que su principal asidero fenomenológico es la fuerza de los hábitos.

\section{FUENTES BIBLIOGRÁFICAS CITADAS Y CONSULTADAS}

Bourdieu, Pierre, "L'identité et la représentation. Éléments pour une réflexion critique sur l'idée de région", en Actes de la Recherche en Sciences Sociales, núm 35, 1980, 63-72.

Bravo Sandoval, Manuel, Agustín Orozco Bravo: anécdotas de un jiquilpense, México, INEHRM, 1998.

Cárdenas del Río, Lázaro, La alameda de Jiquilpan, Morelia, Gobierno del Estado de Michoacán, Secretaría de Urbanismo y Medio Ambiente, Ayuntamiento de Jiquilpan, 2003.

Freud, Sigmund, Malestar en la cultura, Madrid, Alianza Editorial, 1978.

García Urbizu, Francisco, Zamora y Sahuayo. Dos pueblos de arraigada tradición cristiana, Zamora, Talleres "GUíA", 1963.

GIRARD, René, Le bouc émissaire, París, Grasset, 1982. , La violence et le sacré, París, Grasset, 1972.

Gledhill, John, Casi nada. Capitalismo, Estado y los campesinos de la Guaracha, Zamora, El Colegio de Michoacán, 1991. 
Goffman, Erving, Estigma: la identidad deteriorada, Buenos Aires, Amorrortu, 1963.

GonzÁlez y GonzÁlez, Luis, Sahuayo, Morelia, Gobierno del Estado de Michoacán, 1979.

LÉvi-Strauss, Claude, Race et histoire, París, Éditions Gonthier, Unesco, 1961. , Race et culture, París, Éditions Gonthier, Unesco, 1973.

Merton, Robert King, Eléments de théorie et de méthode sociologique, París, Armand Colin, 1997.

Moreno García, Heriberto, Guaracha. Tiempos viejos, tiempos nuevos, Zamora, Colegio de Michoacán, 1994.

Ochoa Serrano, Álvaro, Jiquilpan-Huanimban. Una historia confinada, Morelia, Instituto Michoacano de Cultura, Morevallado Editores, 2003.

, Viajes de michoacanos al norte, Zamora, Colegio de Michoacán, Instituto Michoacano de Cultura, 1998.

Sáenz, Moisés, México integro, México, Fondo de Cultura Económica, 1982.

Schaffhauser, Philippe, "Acción creadora y procesos migratorios: El caso de Jiquilpan, Michoacán”, informe de avance de investigación presentado y discutido en el Centro de Estudios Rurales de El Colegio de Michoacán, 2008.

Simmel, Georg, Le conflit, París, Circé/Poche, 1995.

Sumner, William Graham, Folkways: a study of the sociological importance of usages, manners, customs mores and morals, Nueva York, The New American Library, 1960, 605 p.

Zepeda Patterson, Jorge, "Sahuayo y Jiquilpan: Génesis de la rivalidad por una región 1880-1930”, en Estudios Michoacanos III, Zamora, El Colegio de Michoacán, 1989, 63-80.

FECHA DE RECEPCIÓN DEL ARTí́culo: 30 de junio de 2011

FECHA DE RECEPCIÓN DE LA VERSIÓN FINAL: 13 de diciembre de 2011 